\title{
Modelling factors for Aboriginal and Torres Strait Islander child neurodevelopment outcomes: A latent class analysis
}

\author{
Natalie A. Strobel ${ }^{1,2,4}$ (D) | Alice Richardson ${ }^{2}$ | Carrington C. J. Shepherd ${ }^{3,4}$ | \\ Kimberley E. McAuley ${ }^{1}$ | Rhonda Marriott ${ }^{4}$ | Karen M. Edmond ${ }^{1}$ | Daniel R. McAullay ${ }^{1}$
}

${ }^{1}$ Medical School, The University of Western Australia, Perth, WA, Australia

${ }^{2}$ National Centre for Epidemiology \& Population Health, Research School of Population Health, Australian National University, Canberra, Australia

${ }^{3}$ Telethon Kids Institute, Crawley, WA, Australia

${ }^{4}$ Ngangk Yira Aboriginal Health and Social Equity Research Centre, Murdoch University, Perth, WA, Australia

\section{Correspondence}

Natalie A. Strobel, Medical School, The University of Western Australia, Perth, WA, Australia.

Email: natalie.strobel@uwa.edu.au

\section{Funding information}

This research is supported by an Australian Government Research Training Program (RTP) Scholarship. The funders had no role in the design of the study and collection, analysis, and interpretation of data and in writing the manuscript.

\begin{abstract}
Background: The Australian Early Development Census (AEDC) provides a measure of early child development upon school entry. Understanding which combination of factors influences Aboriginal child neurodevelopment is important to inform policy and practice.
\end{abstract}

Objective: The primary objective was to use latent class analysis (LCA) to model AEDC profiles and identify the highest need profiles. The secondary objective was to determine the associations of these high need profiles on the likelihood of a child becoming developmentally vulnerable.

Methods: We designed a prospective population-based birth cohort study $(n=2715)$ using linked data sets with information on Aboriginal cohort children, and their mothers and siblings in Western Australia. Specific developmental indicators in the 2009 and 2012 AEDC were used to assess developmental vulnerability. LCA methods were used to determine need profiles and their association with developmental vulnerability.

Results: $49.3 \%$ of Aboriginal children were vulnerable on at least one developmental domain, and $37.5 \%$ were vulnerable on two or more domains. LCA found six unique profiles. High needs family, High needs young mother, and Preterm infant comprised $42 \%$ of the cohort and were considered to have high need configurations. These groups were at least 1.7 times as likely to have children who had at least one or two developmental vulnerabilities compared with the Healthy family group.

Conclusion: Many Aboriginal children in Western Australia enter school with at least one developmental vulnerability. This study highlights a range of unique profiles that can be used to empower Aboriginal families for change and develop targeted programmes for improving the early development of young Aboriginal children.

\section{KEYWORDS}

Aboriginal, child neurodevelopment, latent class analysis, population-based study

\section{1 | BACKGROUND}

The first five years of childhood is widely established as a critical time for growth, neurodevelopment, and learning. ${ }^{1}$ Child neurodevelopment involves several interlinked domains of sensorimotor, cognitive-language, and social-emotional function. These domains are influenced by sociocultural, poverty, psychosocial and biological risk factors, and central nervous system development and 
function. ${ }^{2}$ Poor early child neurodevelopment can have long-term impacts into adulthood including schooling outcomes, which can later influence earning capacity. ${ }^{3}$

In Australia, Aboriginal and Torres Strait Islander (Aboriginal) children typically have poorer neurodevelopmental outcomes compared with non-Indigenous Australians and mainstream normative data. ${ }^{4,5}$ These disparities reflect, at least in part, the legacies of colonisation, which has disrupted the capacity of Aboriginal peoples and families to maintain precolonial cultural, spiritual, and organisational practices and has prompted widespread intergenerational trauma. ${ }^{6}$ Despite many Aboriginal families maintaining strong family practices, others experience poor maternal and family mental health, homelessness, violence, and alcohol and/or drug issues. ${ }^{7,8}$ This in turn can affect the capacity of families to provide an environment that can support the optimal neurodevelopment of their children.

Numerous studies have investigated the risk and protective factors associated with child neurodevelopmental outcomes, ${ }^{9-11}$ although few have focused on Australian Aboriginal children. ${ }^{5,12,13}$ Evidence suggests that early child neurodevelopment is not shaped by a singularly important factor or an accumulation of events, but rather multiple aspects of a child's life that are integrated. ${ }^{14,15}$ These findings have been supported by analytic methods that incorporate known risk variables in group analyses to highlight individual pathways, rather than using a more individualistic approach. ${ }^{16}$ Latent class analysis (LCA) is one such example. LCA is a person-centred approach that identifies patterns in individuals that may be experiencing similar combinations of risk and/or protective factors. ${ }^{17}$ Through completing a LCA, profiles can be ascertained that provide interpretable groups, which can subsequently be used to identify those at risk of a particular outcome.

To date, LCA has been used to describe the combination of risk factors and their association with early child neurodevelopment in only a handful of studies. ${ }^{18-21}$ However, only two of these studies have investigated differences within ethnic groups. ${ }^{18,21}$ This is an important distinction as many minority and Indigenous groups have different histories and circumstances that resulted in poor health and social outcomes. Therefore, LCA is likely to be very helpful in understanding which combination of factors is likely to have the greatest impact on child neurodevelopment in these groups. This is particularly important for Australian Aboriginal families. The literature is replete with evidence and commentary from Aboriginal scholars highlighting that the factors that shape the population health and well-being of Aboriginal people are unique in their distribution and impact. ${ }^{6,22,23}$ As a consequence, the solutions that address poor health and well-being in mainstream populations do not necessarily apply in Aboriginal settings. ${ }^{23}$ For Australian Aboriginal families, this type of analysis could lead to better recognition of the combination of factors that influence early Aboriginal child neurodevelopment.

Within Western Australia, data are available for Aboriginal family-linked data sets, which include birth cohorts, their mothers, and siblings. ${ }^{24}$ Focusing on early child neurodevelopment of Aboriginal children aged 5 years in Western Australia, our study was designed to determine patterns of factors that best identify groups of health, social, and community factors from data collected one year prior to the birth of the cohort to when they entered school. Our primary

\section{Synopsis}

\section{Study question}

What are the profiles for Aboriginal and/or Torres Strait Islander (Aboriginal) children who have a high likelihood of becoming developmentally vulnerable?

\section{What's already known}

Aboriginal children have poor health and social experiences, which may influence their neurodevelopmental capacity upon entering school and later in life.

\section{What this study adds}

We have determined unique profiles of Aboriginal children who may experience poor child neurodevelopment upon entering school. These profiles can be used to empower Aboriginal families for change and develop targeted programmes for improving the early development of young Aboriginal children.

objective was to use LCA to model health, social, and community profiles and identify the highest need profiles. Our secondary objective was to determine the impact of these high need profiles on the likelihood of a child becoming developmentally vulnerable, using a holistic measure of children's health and development, the Australian Early Development Census (AEDC).

\section{2 | METHODS}

\subsection{Data source}

This study used population-based data that were systematically linked by the Western Australian Department of Health data linkage staff using probabilistic matching with overt identifiers removed. Databases included the Midwifes Notification System, Birth Register, AEDC, Hospital Morbidity Data Collection, Emergency Department Data Collection, Mental Health Information System, Death Registrations, Department for Child Protection and Family Support, Intellectual Disability Exploring Answers, and the Western Australia Registry of Developmental Anomalies. Only a unique identifier on the individual's clinical information was provided to the researchers, and any identifying information was removed.

\section{2 | Identification of study cohort}

This population-based cohort study included all Aboriginal children born in Western Australia between 2003-2004 and 2006-2007 who participated in the 2009 or 2012 AEDC at age of 5 years.

Children were classified as Aboriginal using the Getting our story right project. ${ }^{24}$ This project developed a validated algorithm, which 
creates a flag for a child that has Indigenous status recorded in a number of Western Australia government administrative data sets. The algorithm uses information from several records from a number of data sets to produce a single flag of Aboriginal and Torres Strait Islander Status for each individual. The Aboriginal and Torres Strait Islander Status Flag provides an indication of a child's status based on multiple records and data sets rather than any one specific record or data collection. It is considered as an approach to identifying Aboriginal persons in administrative data sets. Mother-siblingchild links were identified by the Western Australian Data Linkage Branch, using the Midwives' Notification System and Birth Register. This enabled linkage between maternal health characteristics and our study cohort. Children in the cohort were included if they were born in Western Australia and completed the AEDC at age 5.

The AEDC does not calculate domain scores for children with special needs as these children already receive extensive services. This includes children with chronic medical, physical, or intellectually disabling conditions-for example children with autism, cerebral palsy, or Down's syndrome. Therefore, children were excluded from the cohort if they had missing AEDC domain scores ( $n=323$ ), an intellectual disability, autism, or cerebral palsy $(n=62)$, or were identified as having special needs by teachers within the AEDC $(n=150)$. In cases of multiple births or where a sibling was recorded in the 2012 AEDC, one child from each twin, triplet, or sibling set was randomly selected (excluded $n=324$ ). Siblings were excluded from the analysis if they had no date of birth recorded $(n=221)$ or were $>18$ years of age when AEDC cohort child was born $(n=218)$.

\section{$2.3 \mid$ Exposures}

Maternal age at birth was grouped into five categories: <20, 20-24, $25-29,30-34$, and $\geq 35$ years. Contact with child protection services was considered to have occurred if a child had at least one contact in the form of a notification or substantiation, or if the child had been removed at least once from their family prior to 5 years of age. A mental health contact occurred when a mother had any contact with mental health services (an outpatient service or hospital admission) in the period from one year prior to their cohort child's birth and up to 5 years of age. ${ }^{7}$ Child hospital admissions included admissions to a Western Australia hospital ward for care between discharge from the birth admission to 5 years of age; for mothers, it included the year prior to her child's birth to when their child was 5 years old. Between hospital transfers were included as one admission. The frequency of emergency department presentations was defined as the count of presentations to any emergency department regardless of whether the mother or child was admitted to hospital. The Index of Relative Socio-Economic Disadvantage is categorised into quintiles-from most deprived (1) to least deprived (5). ${ }^{26}$ The Accessibility/Remoteness Index of Australia classifies geographic location on the basis of isolation and distance from service centres and health care facilities. ${ }^{27}$ These data are split into five categories that denote relative geographic remoteness-with categories ranging from least remote (1) (major cities) to most remote (5) (remote area communities). Due to small numbers, inner and outer regional areas were grouped together (quintiles 2-3) as were the highest two socio-economic status quintiles (4-5). Additional infant exposures included infant weight, gestational age, Apgar score, and sex. The total number of pregnancies, the number of siblings, and disabled siblings were also included. Further information on the variables from each database is provided in the Supporting information.

\section{4 | Outcome}

The AEDC is a developmental census that is conducted every three years in Australia, with data collected by teachers with an instrument designed to measure five developmental domains (physical health and well-being, social competence, emotional maturity, language and cognitive skills (school-based) and communication skills, and general knowledge) at age of 5 years. When completing the AEDC for Aboriginal children, there are a number of modifications which have been made to ensure data are appropriately collected. These include (a) the use of Aboriginal school personnel as cultural consultants to support teachers completing the AEDC for Aboriginal children; (b) providing additional information on cultural considerations in the online teaching guide for teachers to consider when answering questions; and (c) additional explanatory items that may be relevant to understanding attendance and performance of Aboriginal children upon entering full-time school. ${ }^{28}$ For this study, we used the two summary indicators which provide data on the developmental vulnerability of children across the five AEDC domains. These were (a) developmentally vulnerable on one or more domain(s); and (b) developmentally vulnerable on two or more domain(s). ${ }^{29,30}$ These indicators are categorised as "yes" or "no" and are based on individual cut-off scores for each domain. Children who score in the bottom $10 \%$ of the national AEDC population distribution for any domain are considered developmentally vulnerable for that domain. These cut-off scores were established in the 2009 AEDC population and have remained the same across collections.

\section{5 | Statistical analysis}

Unadjusted and adjusted generalised linear models with a Poisson family and log-link with robust variances were used to examine the effect of child, maternal, community measures, and hospital utilisation factors on having at least one or two developmental vulnerabilities. ${ }^{31}$ Rate ratio (RR) and $95 \%$ confidence interval $(95 \% \mathrm{Cl}$ ) were calculated. Multivariable regression models were constructed a priori to adjust for the effect of important explanatory variables: child factors (gender of child, birthweight), maternal characteristics (maternal age, gravidity), and socio-economic status.

The LCA was guided by the previous work from Lanza et al. ${ }^{15,17}$ Sixteen variables were included in the analysis with all child, maternal, community measures, and hospital utilisation factors dichotomised (Table 1). Variables were dichotomised to ensure best fit and interpretability of the model. Child protection, number of siblings, maternal age, geographic location, socio-economic 


\begin{tabular}{|c|c|c|c|}
\hline Number & Variable & No risk (coded 0) & Risk (coded 1) \\
\hline 1 & Child sex & Female & Male \\
\hline 2 & Preterm birth & $\geq 37 w^{\prime}$ gestational age & $<37 w k^{\prime}$ gestational age \\
\hline 3 & Birthweight & $\geq 2500$ g weight & $<2500$ g weight \\
\hline 4 & APGAR 5 score & Healthy $\geq 7$ & Unhealthy $<7$ \\
\hline 5 & $\begin{array}{l}\text { Contact with child } \\
\text { protection }\end{array}$ & Not removed & $\begin{array}{l}\text { Had contact or was } \\
\text { removed }\end{array}$ \\
\hline 6 & Siblings & $0-2$ siblings & $\geq 3$ siblings \\
\hline 7 & Disabled siblings & No disabled siblings & Disabled siblings \\
\hline 8 & Maternal age & $\geq 20$ y old & $<20$ y old \\
\hline 9 & Gravidity & $<3$ pregnancies & $\geq 3$ pregnancies \\
\hline 10 & Mental health contact & $\begin{array}{l}\text { No mental health } \\
\text { contact }\end{array}$ & $\begin{array}{l}\text { At least one mental health } \\
\text { contact }\end{array}$ \\
\hline 11 & $\begin{array}{l}\text { Geographic location } \\
\text { (RA) }\end{array}$ & Major cities to remote & Very remote \\
\hline 12 & Socio-economic status & $\begin{array}{l}\text { Least disadvantaged } \\
\text { (quintiles 2-5) }\end{array}$ & $\begin{array}{l}\text { Most disadvantaged } \\
\text { (quintile 1) }\end{array}$ \\
\hline 13 & Child hospitalisation & $<2$ hospitalisations & $\geq 2$ hospitalisations \\
\hline 14 & $\begin{array}{l}\text { Child emergency } \\
\text { presentation }\end{array}$ & $\begin{array}{l}<2 \text { emergency } \\
\text { presentations }\end{array}$ & $\begin{array}{l}\geq 2 \text { emergency } \\
\text { presentations }\end{array}$ \\
\hline 15 & Mother hospitalisation & $<4$ hospitalisations & $\geq 4$ hospitalisations \\
\hline 16 & $\begin{array}{l}\text { Mother emergency } \\
\text { utilisation }\end{array}$ & $\begin{array}{l}<2 \text { emergency } \\
\text { presentations }\end{array}$ & $\begin{array}{l}\geq 2 \text { emergency } \\
\text { presentations }\end{array}$ \\
\hline
\end{tabular}

TAB LE 1 Coding for latent class analysis status, and number of hospitalisations (child and mother) were dichotomised based on the point at which a statistically significant association ( $P$ value $<.05$ ) was achieved in the adjusted regression analysis of the probability that children have at least one development vulnerability. Dichotomising child and mother emergency presentations and gravidity were based on a conservative approach. This included dichotomising a child and mother's emergency presentation as having at least one emergency presentation and gravidity at $\geq 3$ pregnancies. We investigated leaving the variables as outlined in Table 2; however, this did not provide any additional information to the model. To determine the best fit and parsimony of the LCA model, we used information from the Bayesian information criterion (BIC). ${ }^{32}$ For these criteria, the lowest value was considered to indicate the best fitting model. In establishing the classes, we also considered whether each class of the models was qualitatively and quantitatively distinguishable from one another and that groups could be named based on discernible characteristics within the model. Classes were given descriptive names based on the highest probability of the variable response for that class. Interpretation of the model involved recognising that each child's status within each class is not known and that it is the probability of membership for that variable in each class that is provided. The probability of class membership sums to 1 across the classes and reflects the relative proportion of individuals within each class.

Using estimated maximum posterior probability, we assigned a probability of each child being in each class and accepted the highest probability of them being in a particular class. ${ }^{17}$ We then used this to determine how each class profile related to a child's developmental vulnerability. Unadjusted risk ratios were determined using a generalised linear model with a log-binominal function to determine whether developmental vulnerability was associated with the predicted class membership. We did not adjust for covariates as all variables were used to determine each class for the LCA. Data analysis was completed using STATA 15.1.

\subsection{1 | Missing data}

Due to data undergoing multiple linkage passes to minimise both false-positive and false-negative errors along with clerical review to resolve doubtful links, there are little missing data in the cohort at the item level. This is consistent with the findings of Western Australian Data Linkage Branch reviews and periodic audits. ${ }^{33}$ Missing data for socio-economic status $(n=356)$ and geographic remoteness $(n=367)$ from the 2006 census were substituted with data from the census year closest to the birth of the child, where available. If these data were still missing, we then went to the next census year and so on until we had considered all four census years. This method has previously been used by Fairthorne et al. ${ }^{34}$

\section{6 | Community participation}

As part of knowledge sharing and ensuring the data are relevant to communities that they represent, our findings were presented to three Noongar elders and three Aboriginal community members. Our two Aboriginal authors (RM and DM) also had substantial input 
TABLE 2 Sociodemographic characteristics of Aboriginal children with at least one developmental vulnerability, 2009 and 2012 AEDC

\begin{tabular}{|c|c|c|c|}
\hline Characteristics & $\begin{array}{l}\text { All children } \\
n(\%) \\
n=2715\end{array}$ & $\begin{array}{l}\text { Developmentally } \\
\text { vulnerable on } \\
1+\text { domains } \\
n(\%) \\
n=1338(49.3 \%)\end{array}$ & $\begin{array}{l}\text { No develop- } \\
\text { ment vul- } \\
\text { nerabilities } \\
n(\%) \\
n=1377 \\
(50.7 \%)\end{array}$ \\
\hline \multicolumn{4}{|l|}{ Child } \\
\hline \multicolumn{4}{|l|}{ AEDC year } \\
\hline 2009 & $1277(47.0)$ & $653(48.8)$ & $624(45.3)$ \\
\hline 2012 & $1438(53.0)$ & $685(51.2)$ & $753(54.7)$ \\
\hline \multicolumn{4}{|l|}{ Child sex } \\
\hline Male & $1348(49.7)$ & $785(58.7)$ & $563(40.9)$ \\
\hline Female & $1367(50.4)$ & $553(41.3)$ & $814(59.1)$ \\
\hline \multicolumn{4}{|c|}{ Preterm birth (weeks) } \\
\hline$<37$ & $375(13.8)$ & $215(16.1)$ & $160(11.6)$ \\
\hline$\geq 37$ & $2337(86.1)$ & $1121(83.8)$ & $1216(88.3)$ \\
\hline Data missing & NP & NP & NP \\
\hline \multicolumn{4}{|l|}{ Birthweight } \\
\hline $\begin{array}{l}\text { Low birth- } \\
\text { weight } \\
(<2500 \mathrm{~g})\end{array}$ & $323(11.9)$ & $184(13.8)$ & $139(10.1)$ \\
\hline $\begin{array}{l}\text { Normal } \\
\text { birthweight } \\
(\geq 2500 \mathrm{~g})\end{array}$ & $2392(88.1)$ & $1154(86.3)$ & $1238(89.9)$ \\
\hline \multicolumn{4}{|l|}{ APGAR 5 score } \\
\hline$<7$ & $51(1.9)$ & $25(1.9)$ & $26(1.9)$ \\
\hline$\geq 7$ & $2654(97.8)$ & $\geq 90$ & $1345(97.7)$ \\
\hline Data missing & NP & NP & NP \\
\hline \multicolumn{4}{|c|}{ Contact with child protection } \\
\hline No contact & $2055(75.7)$ & $961(71.8)$ & $1094(79.5)$ \\
\hline $\begin{array}{l}\text { At least one } \\
\text { contact } \\
\text { (excl. } \\
\text { removals) }\end{array}$ & $470(17.3)$ & $274(20.5)$ & $196(14.2)$ \\
\hline Removed & $190(7.0)$ & $103(7.7)$ & $87(6.3)$ \\
\hline \multicolumn{4}{|l|}{ Siblings } \\
\hline 0 & 304 (11.2) & $132(9.9)$ & $172(12.5)$ \\
\hline 1 & $619(22.8)$ & $271(20.3)$ & $348(25.3)$ \\
\hline 2 & $600(22.1)$ & $298(22.3)$ & $302(21.9)$ \\
\hline$\geq 3$ & $1192(43.9)$ & $637(47.6)$ & $555(40.3)$ \\
\hline \multicolumn{4}{|l|}{ Disabled siblings } \\
\hline Disabilities & $261(9.6)$ & $140(10.5)$ & $121(8.8)$ \\
\hline $\begin{array}{l}\text { No } \\
\text { disabilities }\end{array}$ & $2454(90.4)$ & $1198(89.5)$ & $1256(91.2)$ \\
\hline \multicolumn{4}{|l|}{ Mother } \\
\hline \multicolumn{4}{|c|}{ Maternal age (years) } \\
\hline$<20$ & $624(23.0)$ & $334(25.0)$ & $290(21.1)$ \\
\hline $20-24$ & $906(33.4)$ & $434(32.4)$ & 472 (34.3) \\
\hline $25-29$ & $609(22.4)$ & $293(21.9)$ & $316(23.0)$ \\
\hline
\end{tabular}

TABLE 2 (Continued)

\begin{tabular}{|c|c|c|c|}
\hline Characteristics & $\begin{array}{l}\text { All children } \\
n(\%) \\
n=2715\end{array}$ & $\begin{array}{l}\text { Developmentally } \\
\text { vulnerable on } \\
1+\text { domains } \\
n(\%) \\
n=1338(49.3 \%)\end{array}$ & $\begin{array}{l}\text { No develop- } \\
\text { ment vul- } \\
\text { nerabilities } \\
n(\%) \\
n=1377 \\
(50.7 \%)\end{array}$ \\
\hline $30-34$ & $389(14.3)$ & 181 (13.5) & 208 (15.1) \\
\hline $35+$ & $187(6.9)$ & $96(7.2)$ & $91(6.6)$ \\
\hline \multicolumn{4}{|l|}{ Gravidity } \\
\hline 0 & $683(25.2)$ & $326(24.4)$ & $357(25.9)$ \\
\hline 1 & $581(21.4)$ & $265(19.8)$ & $316(23.0)$ \\
\hline 2 & $451(16.6)$ & $222(16.6)$ & $229(16.6)$ \\
\hline$\geq 3$ & $997(36.7)$ & $523(39.1)$ & $474(34.4)$ \\
\hline Data missing & NP & NP & NP \\
\hline \multicolumn{4}{|c|}{ Mental health contact } \\
\hline $\begin{array}{c}\text { At least } 1 \\
\text { contact }\end{array}$ & $1096(40.4)$ & $618(46.2)$ & $478(34.7)$ \\
\hline No contact & $1619(59.6)$ & $720(53.8)$ & $899(65.3)$ \\
\hline \multicolumn{4}{|l|}{ Community } \\
\hline \multicolumn{4}{|c|}{ Geographic location } \\
\hline Major city & $973(35.8$ & $455(34.0)$ & $518(37.6)$ \\
\hline Regional & $626(23.1)$ & $298(22.3)$ & $328(23.8)$ \\
\hline Remote & $399(14.7)$ & $190(14.2)$ & $209(15.8)$ \\
\hline Very remote & $571(21.0)$ & $314(23.5)$ & $257(18.7)$ \\
\hline Data missing & $146(5.4)$ & $81(6.1)$ & $65(4.7)$ \\
\hline \multicolumn{4}{|c|}{ Socio-economic status } \\
\hline $\begin{array}{l}\text { Most disad- } \\
\text { vantaged } 1\end{array}$ & $1530(56.4)$ & $813(60.8)$ & $717(52.1)$ \\
\hline 2 & $544(20.0)$ & $240(17.9)$ & $304(22.1)$ \\
\hline 3 & $276(10.2)$ & $116(8.7)$ & $160(11.6)$ \\
\hline $\begin{array}{l}\text { Least disad- } \\
\text { vantaged } \\
4-5\end{array}$ & 219 (8.1) & $88(6.6)$ & $131(9.5)$ \\
\hline Data missing & $146(5.4)$ & $81(6.1)$ & $65(4.7)$ \\
\hline \multicolumn{4}{|l|}{ Hospital utilisation } \\
\hline \multicolumn{4}{|c|}{ Child hospitalisation } \\
\hline 0 & $665(24.5)$ & $263(20.0)$ & $402(29.2)$ \\
\hline 1 & $770(28.4)$ & $345(25.8)$ & $425(30.9)$ \\
\hline 2 & $503(18.5)$ & $261(19.5)$ & $242(17.6)$ \\
\hline 3 & $292(10.1)$ & $167(12.5)$ & $125(9.1)$ \\
\hline 4 & $169(6.2)$ & $104(7.8)$ & $65(4.7)$ \\
\hline$\geq 5$ & $316(11.4)$ & $198(14.8)$ & $118(8.6)$ \\
\hline \multicolumn{4}{|c|}{ Child emergency presentation } \\
\hline 0 & $82(3.0)$ & $37(2.8)$ & $45(3.3)$ \\
\hline 1 & $193(7.1)$ & $95(7.1)$ & $98(7.1)$ \\
\hline 2 & $177(6.5)$ & $72(5.4)$ & $105(7.6)$ \\
\hline 3 & $196(7.2)$ & $77(5.8)$ & $119(8.6)$ \\
\hline 4 & $189(7.0)$ & $91(6.8)$ & $98(7.1)$ \\
\hline$\geq 5$ & $1878(69.2)$ & $966(72.2)$ & $912(66.2)$ \\
\hline
\end{tabular}


TABLE 2 (Continued)

\begin{tabular}{|c|c|c|c|}
\hline Characteristics & $\begin{array}{l}\text { All children } \\
n(\%) \\
n=2715\end{array}$ & $\begin{array}{l}\text { Developmentally } \\
\text { vulnerable on } \\
1+\text { domains } \\
n(\%) \\
n=1338(49.3 \%)\end{array}$ & $\begin{array}{l}\text { No develop- } \\
\text { ment vul- } \\
\text { nerabilities } \\
n(\%) \\
n=1377 \\
(50.7 \%)\end{array}$ \\
\hline \multicolumn{4}{|c|}{ Mother hospitalisation } \\
\hline 0 & NP & NP & NP \\
\hline 1 & $275(10.1)$ & $115(8.6)$ & $160(11.6)$ \\
\hline 2 & $447(16.5)$ & $184(13.8)$ & $263(19.1)$ \\
\hline 3 & $502(18.5)$ & $216(16.1)$ & $286(20.8)$ \\
\hline 4 & $395(14.6)$ & $207(15.5)$ & $188(13.7)$ \\
\hline$\geq 5$ & $1095(40.3)$ & $616(46.0)$ & $479(34.8)$ \\
\hline \multicolumn{4}{|c|}{ Mother emergency utilisation } \\
\hline 0 & $176(6.5)$ & $78(5.8)$ & $98(7.1)$ \\
\hline 1 & $228(8.4)$ & $90(6.7)$ & $138(10.0)$ \\
\hline 2 & $212(7.8)$ & $86(6.4)$ & $126(9.2)$ \\
\hline 3 & $193(7.1)$ & $89(6.7)$ & $104(7.6)$ \\
\hline 4 & $196(7.2)$ & $93(7.0)$ & $103(7.5)$ \\
\hline$\geq 5$ & $1710(63.0)$ & $902(67.4)$ & 808 (56.7) \\
\hline
\end{tabular}

Note: $\geq 90$, not publishable due to high numbers and confidentiality restrictions; NP, not publishable due to small numbers and confidentiality restrictions.

into the interpretation of the data. This group decided on the descriptive names for the six classes identified from the LCA and discussed whether the groups were representative of the community. It is important to note that within Western Australia there is diversity among Aboriginal peoples and that data should be interpreted with caution for any one community or group.

\subsection{Ethics approval}

This study has ethical approval from the Western Australian Department of Health Human Research Ethics Committee (HREC) (2014/21), the Western Australian Aboriginal Health Ethics Committee (416), the Australian National University Ethics Committee (2018/013), Murdoch University HREC (2014/025), and the University of Western Australia HREC (RA/4/20/4920).

\section{3 | RESULTS}

In Western Australia, 2715 Aboriginal children aged 5 years completed the AEDC with $47.0 \%(1277 / 2715)$ completing the AEDC in 2009 and $53.0 \%(1438 / 2715)$ in 2012 . In total, 49.3\% (1338/2715) had at least one developmental vulnerability, while $37.5 \%$ (825 of 2202) had at least two developmental vulnerabilities (Tables 2 and S1). Of those children with at least one developmental vulnerability, $16.1 \%$ (215) were born prematurely (<37 weeks) compared with $11.6 \%(160)$ who had no developmental vulnerabilities. Close to half $(46.2 \% ; n=618)$ of
Aboriginal children with at least one developmental vulnerability had a mother with a mental health contact compared with $34.7 \%$ (478) of children who had no developmental vulnerabilities (Table 3).

Children who had at least one contact with child protection services $(58.3 \%$; $n=274$ ) were 1.2 times as likely to be developmentally vulnerable on one or more domains compared to those with no contacts (46.8\%; $n=961$; Table 3). Children whose mother had experienced a mental health contact between 1 year prior to and up to 5 years after birth had 1.2 times the risk of having at least one developmental vulnerability compared with children who whose mother had experienced no mental health contacts. Those children who were in the most disadvantaged socio-economic group were 1.3 times as likely to have a developmental vulnerability compared with those in the least disadvantaged group. For children who had at least one developmental vulnerability and at least one hospital admission, there was increasing risk associated with an increasing number of admissions. Children with two or more developmental vulnerabilities had a similar risk profile as children who had at least one developmental vulnerability (Table S2).

We fitted models that had one to six latent classes (Table 4). After assessing the models for (1) BIC values, (2) distinguishable variables between classes, and (3) groups that could be named based on discernible characteristics, it was determined the six-class model was the most appropriate.

The probability of belonging to a class ranged from $9 \%$ to $22 \%$ (Table 5). The first identified class was the "Healthy family" with a $19 \%$ probability of being included in this class. These families had children who had healthy birth outcomes and mothers who had the lowest probability of having any additional needs. "High needs family" contained $22 \%$ of the sample. This group had the overall highest number of child, mother, and community risks making it a complicated and high needs group. Children had a high probability of having contact with child protection services (47.2\%), high levels of socio-economic disadvantage (69.7\%), having more than three siblings (88.1\%), having a maternal mental health contact (69.9\%), and having four or more maternal hospital admissions (84.5\%).

"Preterm infant" were the smallest class and comprised $9 \%$ of the sample. This group had a high probability of being preterm (97.4\%) and having a low birthweight (91.1\%), contact with child protection services (33.8\%), and children having two or more hospital admissions (84.9\%). Maternal mental health contacts (51.9\%) were also prominent features of this class.

The "High needs young mother" class was $11 \%$ of the sample and had $100 \%$ probability of having a maternal mental health contact. In addition, the majority of the children in this class were born to young mothers (57.8\%), lived in a very remote area (39.5\%), with high levels of socio-economic disadvantage $(70.9 \%$ in the highest quintile), and had contact with child protection services (45.3\%). In comparison, the "Young mother" class (19\% of the sample) was characterised by a relatively small proportion of maternal mental health contacts (16.6\%), $47.5 \%$ young mothers, 
TAB LE 3 Associations between sociodemographic characteristics and Aboriginal children with at least one developmental vulnerability, 2009 and 2012 AEDC

\begin{tabular}{|c|c|c|c|c|}
\hline Characteristics & $\begin{array}{l}\text { Total number of } \\
\text { children } \\
n(\%) \\
n=2715\end{array}$ & $\begin{array}{l}\text { Number with at least } 1 \\
\text { developmentally vulnerable } \\
n(\%) \\
n=1338\end{array}$ & $\begin{array}{l}\text { Unadjusted rate ratio } \\
\text { ( } 95 \% \text { confidence interval) }\end{array}$ & $\begin{array}{l}\text { Adjusted rate ratio } \\
\left(95 \% \text { confidence interval) }{ }^{*}\right.\end{array}$ \\
\hline \multicolumn{5}{|l|}{ Child } \\
\hline \multicolumn{5}{|l|}{ AEDC year } \\
\hline 2009 & $1277(47.0)$ & $653(51.1)$ & 1.00 (Reference) & 1.00 (Reference) \\
\hline \multicolumn{5}{|l|}{ Child sex } \\
\hline Male & $1348(49.7)$ & 785 (58.2) & $1.44(1.33,1.56)$ & $1.46(1.35,1.59)$ \\
\hline Female & $1367(50.4)$ & $553(40.5)$ & 1.00 (Reference) & 1.00 (Reference) \\
\hline \multicolumn{5}{|l|}{ Preterm birth (weeks) } \\
\hline \multicolumn{5}{|l|}{ Birthweight } \\
\hline $\begin{array}{l}\text { Low birthweight } \\
(<2500 \mathrm{~g})\end{array}$ & $323(11.9)$ & $184(57.0)$ & $1.18(1.06,1.31)$ & $1.14(1.00,1.30)$ \\
\hline $\begin{array}{l}\text { Normal birthweight } \\
(\geq 2500 \mathrm{~g})\end{array}$ & 2392 (88.1) & 1154 (48.2) & 1.00 (Reference) & 1.00 (Reference) \\
\hline \multicolumn{5}{|l|}{ 5-min Apgar score } \\
\hline$<7$ & $51(1.9)$ & $25(49.0)$ & $0.99(0.75,1.32)$ & $0.97(0.73,1.30)$ \\
\hline$\geq 7$ & $2654(97.8)$ & 1309 (49.3) & 1.00 (Reference) & 1.00 (Reference) \\
\hline \multicolumn{5}{|c|}{ Contact with child protection } \\
\hline No contact & $2055(75.7)$ & $961(46.8)$ & 1.00 (Reference) & 1.00 (Reference) \\
\hline 2 & $600(22.1)$ & $298(49.7)$ & $1.13(1.01,1.28)$ & $1.12(0.99,1.27)$ \\
\hline$\geq 3$ & $1192(43.9)$ & $637(53.4)$ & $1.22(1.10,1.35)$ & $1.23(1.09,1.40)$ \\
\hline \multicolumn{5}{|l|}{ Disabled siblings } \\
\hline Disabilities & $261(9.6)$ & $140(53.6)$ & $1.10(0.97,1.24)$ & $1.04(0.92,1.18)$ \\
\hline No disabilities & $2454(90.4)$ & $1198(48.8)$ & 1.00 (Reference) & 1.00 (Reference) \\
\hline \multicolumn{5}{|l|}{ Mother } \\
\hline \multicolumn{5}{|l|}{ Maternal age (years) } \\
\hline$<20$ & $624(23.0)$ & $334(53.5)$ & $1.11(1.00,1.24)$ & $1.33(1.16,1.53)$ \\
\hline $20-24$ & $906(33.4)$ & $434(47.9)$ & $1.00(0.89,1.11)$ & $1.07(0.96,1.20)$ \\
\hline $25-29$ & $609(22.4)$ & $293(48.1)$ & 1.00 (Reference) & 1.00 (Reference) \\
\hline $30-34$ & $389(14.3)$ & $181(46.5)$ & $0.97(0.85,1.11)$ & $0.93(0.82,1.07)$ \\
\hline$\geq 35$ & $187(6.9)$ & $96(51.3)$ & $1.07(0.91,1.25)$ & $1.05(0.88,1.23)$ \\
\hline \multicolumn{5}{|l|}{ Gravidity } \\
\hline 0 & $683(25.2)$ & $326(47.7)$ & $0.97(0.86,1.10)$ & $0.89(0.79,1.01)$ \\
\hline 1 & $581(21.4)$ & $265(45.6)$ & $0.93(0.81,1.05)$ & $0.89(0.78,1.02)$ \\
\hline 2 & $451(16.6)$ & $222(49.2)$ & 1.00 (Reference) & 1.00 (Reference) \\
\hline$\geq 3$ & $997(36.7)$ & $523(52.5)$ & $1.07(0.95,1.19)$ & $1.13(1.00,1.27)$ \\
\hline
\end{tabular}


TABLE 3 (Continued)

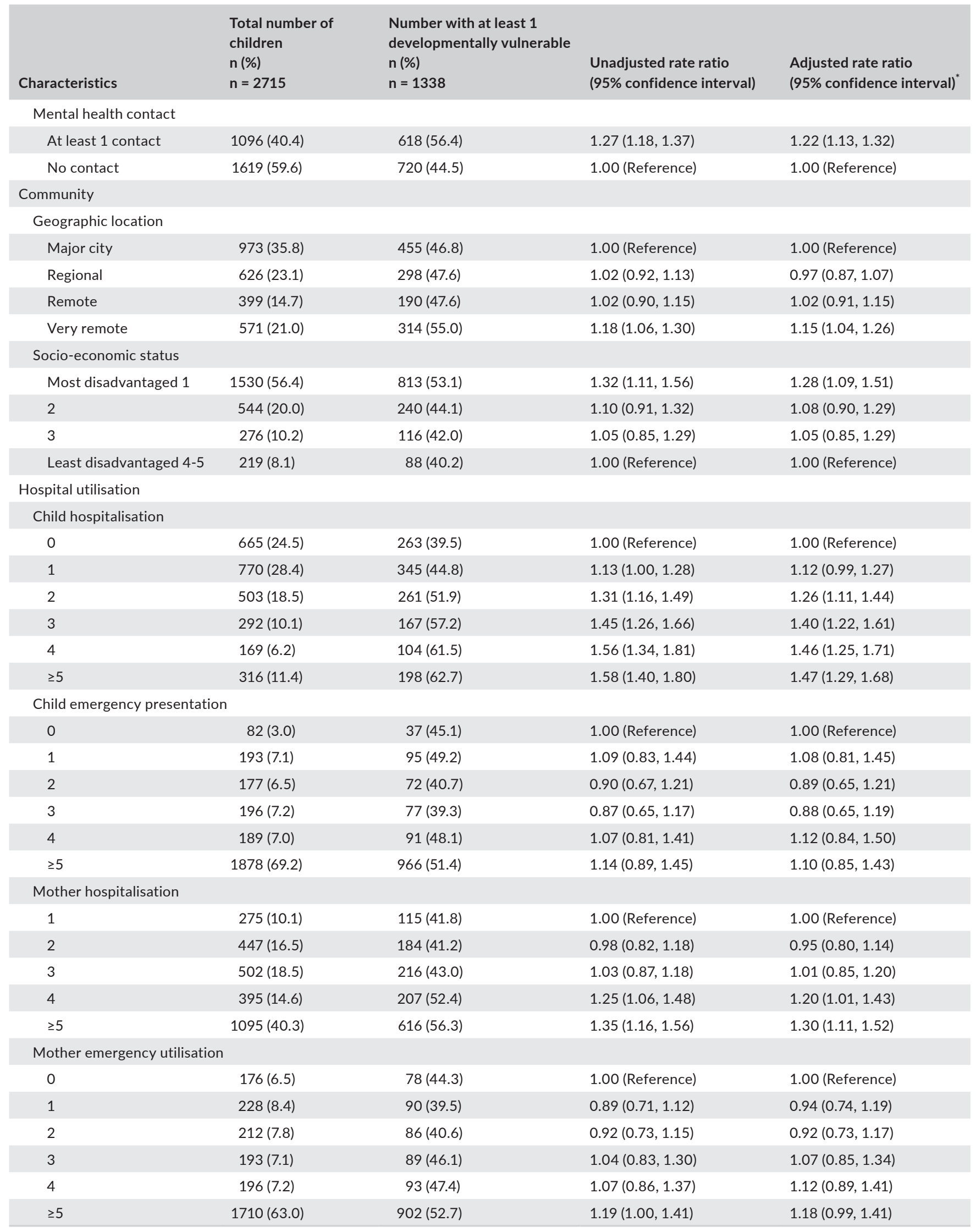

*Adjusted for sex, mother's age, SES, gravidity, preterm birth. 
and a high level of socio-economic disadvantage (61.5\%). The last class was named "Larger family" and contributed to $20 \%$ of the sample. Overall, these families are typified as having three or more siblings (76.4\%); however, they had few other outstanding features.

After assigning each child to their predicted class membership, the proportion of children with at least one development vulnerability ranged from $34.3 \%$ (196) in the "Healthy family" group to $57.9 \%$ (199) among the High needs young mothers' group (Table 6). Regression model results highlighted that, when compared with the Healthy family class, children in all other classes were at an elevated risk of having at least one developmental vulnerability (Table 6). Risk ratios were between 1.5 and 1.7 for High needs family, Preterm infant, High needs young mother, and Young mother classes, and of a smaller magnitude for the Large family class. This pattern of results (and effect sizes) was similar when modelling the risk of having two or more developmental vulnerabilities (Table 6).

\section{4 | COMMENT}

\section{1 | Principal findings}

This population-based cohort study found $49 \%$ of Aboriginal children were vulnerable on at least one developmental domain and $38 \%$ were vulnerable on at least two or more developmental domains. We identified six unique groups based on our LCA (using data from children, their mothers, siblings, and community) and input from an Aboriginal community consultation group: Healthy family; High needs family; Preterm infant; High needs young mother; Young

\begin{tabular}{|lllll|}
\hline & \multicolumn{2}{l}{ Measures of fit } \\
\cline { 2 - 5 } Number classes & $\begin{array}{l}\text { Likelihood ratio } \\
\text { G-square }\end{array}$ & $\begin{array}{l}\text { Degrees of } \\
\text { freedom }\end{array}$ & AIC & BIC \\
\hline 1 & 7860.49 & 16 & 44819.02 & 44913.52 \\
\hline 2 & 6413.91 & 33 & 43406.44 & 43601.35 \\
\hline 3 & 5158.10 & 49 & 42182.63 & 42472.05 \\
\hline 4 & 4614.29 & 65 & 41670.82 & 42054.75 \\
\hline 5 & 4218.71 & 83 & 41374.24 & 41864.48 \\
\hline 6 & 4161.65 & 97 & 41282.18 & 41855.11 \\
\hline
\end{tabular}

TABLE 4 Measures of model fit for latent class analysis

TAB LE 5 Conditional probabilities and distributions of risk for a six-class latent analysis

\begin{tabular}{|c|c|c|c|c|c|c|}
\hline Variables & $\begin{array}{l}\text { Healthy } \\
\text { family }\end{array}$ & $\begin{array}{l}\text { High needs } \\
\text { family }\end{array}$ & $\begin{array}{l}\text { Preterm } \\
\text { infant }\end{array}$ & $\begin{array}{l}\text { High needs } \\
\text { young mother }\end{array}$ & $\begin{array}{l}\text { Young } \\
\text { mother }\end{array}$ & $\begin{array}{l}\text { Large } \\
\text { family }\end{array}$ \\
\hline C: Male & 0.532 & 0.505 & 0.418 & 0.451 & 0.556 & 0.456 \\
\hline C: Low birthweight & 0.000 & 0.059 & 0.911 & 0.115 & 0.047 & 0.023 \\
\hline C: 5 -min Apgar score $<7$ & 0.010 & 0.008 & 0.063 & 0.038 & 0.005 & 0.023 \\
\hline C: $\geq 3$ siblings & 0.000 & 0.881 & 0.408 & 0.115 & 0.243 & 0.764 \\
\hline C: Had disabled siblings & 0.020 & 0.183 & 0.129 & 0.031 & 0.067 & 0.126 \\
\hline$M:<20$ y old & 0.267 & 0.011 & 0.223 & 0.578 & 0.475 & 0.007 \\
\hline $\mathrm{M}: \geq 3$ pregnancies & 0.006 & 0.819 & 0.340 & 0.000 & 0.016 & 0.779 \\
\hline M: At least one mental health contact & 0.129 & 0.699 & 0.519 & 1.000 & 0.166 & 0.201 \\
\hline$C: \geq 2$ emergency presentations & 0.831 & 0.963 & 0.931 & 0.915 & 0.976 & 0.799 \\
\hline$M: \geq 5$ hospitalisations & 0.126 & 0.845 & 0.700 & 0.785 & 0.717 & 0.283 \\
\hline \multirow[t]{2}{*}{$M: \geq 2$ emergency presentations } & 0.619 & 0.990 & 0.896 & 0.974 & 1.000 & 0.697 \\
\hline & \multicolumn{6}{|c|}{ Class membership } \\
\hline Probabilities & 0.19 & 0.22 & 0.09 & 0.11 & 0.19 & 0.20 \\
\hline Standard error & 0.02 & 0.02 & 0.01 & 0.02 & 0.02 & 0.02 \\
\hline
\end{tabular}

Note: C, child-related variable; $\mathrm{CP}$, child protection; $\mathrm{M}$, mother-related variable. 


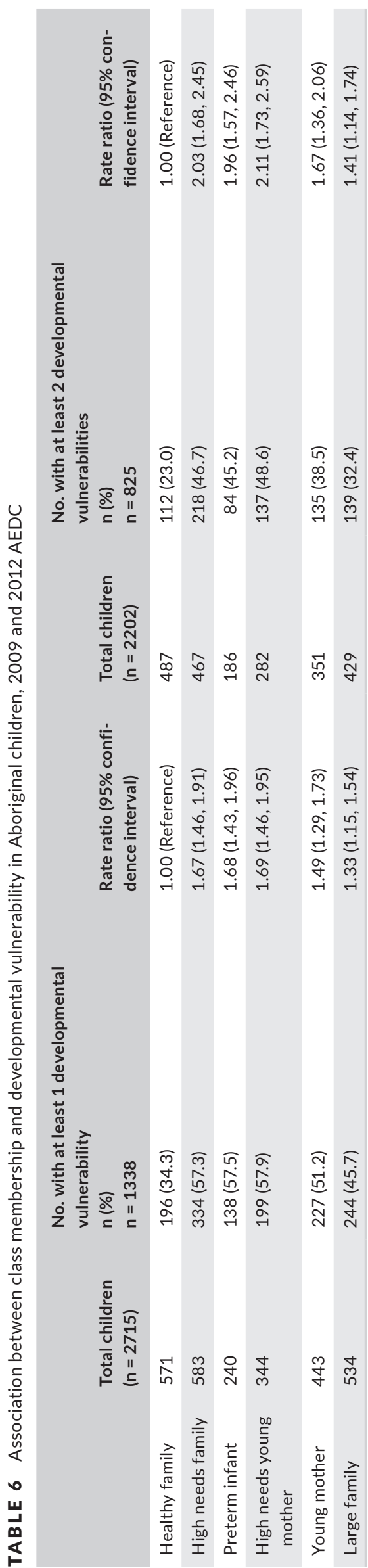

mother; and Large family. High needs family, High needs young mother, and Preterm infant comprised $42 \%$ of the cohort and were considered to have high need configurations. These groups were at least 1.7 times as likely to have children who had at least one or two developmental vulnerabilities compared with the Healthy family group (Table 5).

\subsection{Strengths of the study}

The strengths of this study include the large population-based data set which had minimal missing data. We included a number of important variables in the cohort and linked our cohort to information on their mothers and siblings to provide a more comprehensive picture of the cohort's family. We also had Aboriginal community participation in the interpretation of these results, which provided important contextual information.

\subsection{Limitations of the data}

The study has some limitations. We only used administrative data sources, which do not include important social variables that are often available in survey data. As a result, we have not captured the full spectrum of stressors and protective factors a family may have. There may have been misclassification error using maximum posterior probability as some children may have similar probabilities of being in two classes. By using the Getting our story right indicator on children of a young age, we have assumed children identify as being Aboriginal; however, some children who have been included may not identify as being Aboriginal. There has been some criticism of whether the AEDC for Aboriginal children is appropriate, particularly in remote areas of Australia, which should be considered when interpreting results. Due to the type of analysis that was completed, it was difficult to compare across studies whether these classes are valid; however, our Aboriginal community group found the classes to be believable.

\section{4 | Interpretation}

Our initial analysis found a number of important individual risk factors that were associated with a child having at least one or more developmental vulnerabilities. Similar to our study, it has previously been reported that prematurity, ${ }^{35}$ maternal mental health, ${ }^{36}$ maternal age $<20$ years at delivery, ${ }^{5}$ and male children ${ }^{13}$ have been associated with developmental vulnerabilities in Aboriginal children. In addition, we found important variables such as contact with child protection agencies, children in the lowest socio-economic bracket, and child and maternal hospitalisations to be risk factors for developmental vulnerability, which are comparable to developmentally vulnerable children internationally. ${ }^{11,37}$ We also found similar risks for children who had at least two or more developmental vulnerabilities. As developmental vulnerabilities increase, children are more likely to have trouble with numeracy and literacy as they go through school. ${ }^{38}$ As a result, ensuring this group has access to early 
learning opportunities is imperative for their positive transition to school.

Two-fifths (42\%) of children were characterised within three high need groups: High needs family, High needs young mother, and Preterm infant. Interpretation of these classes should proceed with caution as no one child falls "neatly" into any one class and each child has some probability of falling into each class. Each child may also have other important social characteristics that have not been accounted for in this analysis. The High needs family group was the largest group and accounted for $22 \%$ of the sample. Although risks were not the same, similar complex multiple risk groups have been identified in other LCA studies and have been found to be associated with poor child neurodevelopment. ${ }^{19-21}$ It is unsurprising that a multiple need group was identified in our cohort given the complex number of factors that can influence child neurodevelopment. Improvements in quality and access to mental health services in remote areas and for lower socio-economic groups could provide substantial improvements to these families and provide clear pathways to support them.

Maternal stress features prominently within half of the classesparticularly the High needs young mother class, which is defined by young mothers living in very remote areas in the lowest socioeconomic bracket, and often with a history of contact with child protection services. A possible reason for this group is the lack of available services in remote areas, which results in less opportunity to engage in prevention and early treatment of mental health problems. As mental health problems escalate, there is an increase in the level of service provision needed and caring for their young children becomes difficult. This lack of mental health services and possible family support for young mothers in remote areas is likely to result in the involvement of child protection. These factors are often underpinned by poverty and lack of social capital. ${ }^{39}$ However, this is in direct contrast to the Young mother's group who are also in the lowest socio-economic quintile but have a far less probability of having poor maternal mental health (16.6\%) and having contact with child protection (15.2\%). Further work to discern the differences between these two groups of young mothers is fundamental for delivering targeted programmes of care.

We reported our findings back to our Aboriginal community group who provided final agreement on the names of the six classes in this paper. An important consideration by our community group was that families were not at "risk" but "needed" additional support. We have altered our objectives, results, and findings to consider the LCA as need profiles not risk profiles. After discussion about the attributes within each of these classes, our community group found that the data were believable for Western Australian families and were even able to name these groups in their local language. We have not provided these names in this manuscript due to diversity of language and culture groups within Western Australia. Improving access to services, particularly for mental health, was an important solution to improving the health and well-being of Aboriginal families. Also, additional data such as whether mothers had previous contact with the justice or the child protection system would have provided important background; however, these data were unavailable for our study.

\section{5 | Conclusion}

Our results have important implications for policy and programme development. This study found that $42 \%$ of the cohort were grouped as High needs family, High needs young mother, and Preterm infant. Addressing important issues such as child protection, maternal mental health, and low socio-economic status is important for improving the early neurodevelopment trajectories of young Aboriginal children. Affirmative policies, improving access to services, reducing social inequalities, and empowering families to support the developmental needs of their children are important to improve school readiness.

\section{ACKNOWLEDGEMENTS}

We would like to thank Aboriginal elders Millie Penny, Doreen Nelson, and Gladys Yarran, and community members Jocelyn Jones, Jade Maddox, and Sharynne Hamilton for their time and contributions in this project. The Noongar people are from the south-west of Western Australia and are the traditional owners of these lands. We would also like to thank Mr Daniel Christenson (Telethon Kids Institute) who provided some guidance for the latent class analysis. We acknowledge the support of the Western Australian Data Linkage Branch and Data Custodians in this project.

\section{DISCLAIMER}

This paper uses data from the Australian Early Development Census (AEDC). The AEDC is funded by the Australian Government Department of Education and Training. The findings and views reported are those of the author and should not be attributed to the Department or the Australian Government.

\section{ORCID}

Natalie A. Strobel (iD https://orcid.org/0000-0002-2962-5704

\section{REFERENCES}

1. Shonkoff JP, Marshall PC. Neurological basis of developmental vulnerability. In: Shonkoff JP, Meisels SJ, eds. Handbook of early childhood intervention (2nd ed). Cambridge: Cambridge University Press; 2000:204-228.

2. Walker SP, Wachs TD, Gardner JM, et al. Child development: risk factors for adverse outcomes in developing countries. Lancet. 2007;369(9556):145-157.

3. Grantham-McGregor S, Cheung YB, Cueto S, et al. Developmental potential in the first 5 years for children in developing countries. Lancet. 2007;369(9555):60-70.

4. Brinkman SA, Gialamas A, Rahman A, et al. Jurisdictional, socioeconomic and gender inequalities in child health and development: analysis of a national census of 5-year-olds in Australia. BMJ Open. 2012;2(5):1-14.

5. McDonald J, Webster V, Knight J, Comino E. The Gudaga Study: development in 3-year-old urban Aboriginal children. J Paediatr Child Health. 2014;50(2):100-106. 
6. Paradies Y. Colonisation, racism and indigenous health. J Popul Res. 2016;33(1):83-96.

7. Lima F, Shepherd C, Wong J, O'Donnell M, Marriott R. Trends in mental health related contacts among mothers of Aboriginal children in Western Australia (1990-2013): a linked data population-based cohort study of over 40000 children. BMJ Open. 2019;9(7):e027733.

8. Australian Health Ministers' Advisory Council. Aboriginal and Torres Strait Islander Health Performance Framework 2017 Report. Canberra: AHMAC; 2017.

9. Taylor CL, Christensen D, Lawrence D, Mitrou F, Zubrick SR. Risk factors for children's receptive vocabulary development from four to eight years in the longitudinal study of Australian children. PLoS ONE. 2013;8(9):e73046.

10. Jensen SKG, Berens AE, Nelson CA 3rd. Effects of poverty on interacting biological systems underlying child development. Lancet Child Adolesc Health. 2017;1(3):225-239.

11. Walker SP, Wachs TD, Grantham-McGregor S, et al. Inequality in early childhood: risk and protective factors for early child development. Lancet. 2011;378(9799):1325-1338.

12. McDonald JL, Comino E, Knight J, Webster V. Developmental progress in urban Aboriginal infants: a cohort study. J Paediatr Child Health. 2012;48(2):114-121.

13. Edmond KM, Tung S, McAuley K, Strobel N, McAullay D. Improving developmental care in primary practice for disadvantaged children. Arch Dis Child. 2018;104(4):372-380.

14. Evans GW, Kim P. Childhood poverty, chronic stress, self-regulation, and coping. Child Dev Perspect. 2013;7(1):43-48.

15. Lanza ST, Rhoades BL, Nix RL, Greenberg MT. Conduct Problems Prevention Research G. Modeling the interplay of multilevel risk factors for future academic and behavior problems: a person-centered approach. Dev Psychopathol. 2010;22(2):313-335.

16. Kagan J. Kinds of individuals defined by patterns of variables. Dev Psychopathol. 2018;30(4):1197-1209.

17. Collins LM, Lanza ST. Latent Class and Latent Transition Analysis : With Applications in the Social, Behavioral, and Health Sciences. Hoboken, United States: Wiley; 2010.

18. Roy AL, Raver CC. Are all risks equal? Early experiences of poverty-related risk and children's functioning. J Fam Psychol. 2014;28(3):391-400.

19. Christensen D, Taylor CL, Zubrick SR. Patterns of multiple risk exposures for low receptive vocabulary growth 4-8 years in the longitudinal study of australian children. PLoS ONE. 2017;12(1):e0168804.

20. Oliver BR, Kretschmer T, Maughan B. Configurations of early risk and their association with academic, cognitive, emotional and behavioural outcomes in middle childhood. Soc Psychiatry Psychiatr Epidemiol. 2014;49(5):723-732.

21. Rhoades BL, Greenberg MT, Lanza ST, Blair C. Demographic and familial predictors of early executive function development: contribution of a person-centered perspective. J Exp Child Psychol. 2011;108(3):638-662.

22. Dudgeon P, Milroy H, Walker R, eds. Working Together: Aboriginal and Torres Strait Islander Mental Health and Wellbeing Principles and Practice, 2nd edn. Canberra: Australian Government Department of the Prime Minister and Cabinet; 2014.

23. Milroy $\mathrm{H}$. Understanding the Lives of Aboriginal Children and Families. In: Dudgeon P, Milroy H, Walker R, eds. Working Together: Aboriginal and Torres Strait Islander Mental Health and Wellbeing Principles and Practice, 2nd edn. Canberra: Australian Government Department of the Prime Minister and Cabinet; 2014:373-382.

24. Holman CD, Bass AJ, Rosman DL, et al. A decade of data linkage in Western Australia: strategic design, applications and benefits of the WA data linkage system. Aust Health Rev. 2008;32(4):766-777.
25. Christensen D, Davis G, Draper G, et al. Evidence for the use of an algorithm in resolving inconsistent and missing Indigenous status in administrative data collections. Aust $J$ Soc Issues. 2014;49(4):423-443.

26. Pink B. Socio-Economic Indexes for Areas (SEIFA) - Technical Paper 2006. Canberra: Australian Bureau of Statistics; 2008.

27. Department of Health and Aged Care. Measuring remoteness: Accessibility/remoteness index of Australia (ARIA). Revised edition. Canberra: Commonwealth of Australia; 2001.

28. Commonwealth of Australia. The AEDI and Aboriginal and Torres Strait Islander children. 2019. https://www.aedc.gov.au/about-theaedc/history/validation-and-trial-of-the-aedi/the-aedi-and-indig enous-children (accessed 3 July 2019).

29. Department of Education and Training. Australian Early Development Census Data Guidelines. Canberra: Commonwealth of Australia; 2017.

30. Brinkman SA, Gregory TA, Goldfeld S, Lynch JW, Hardy M. Data resource profile: the Australian early development index (AEDI). Int J Epidemiol. 2014;43(4):1089-1096.

31. Zou G. A modified poisson regression approach to prospective studies with binary data. Am J Epidemiol. 2004;159(7):702-706.

32. Nylund KL, Asparoutiov T, Muthen BO. Deciding on the number of classes in latent class analysis and growth mixture modeling: A Monte Carlo simulation study. Struct Equ Modeling. 2007;14(4):535-569.

33. Sprivulis P, Da Silva JA, Jacobs I, Jelinek G, Swift R. ECHO: the Western Australian emergency care hospitalisation and outcome linked data project. Aust N Z J Public Health. 2006;30(2):123-127.

34. Fairthorne J, Walker R, de Klerk N, Shepherd C. Early mortality from external causes in Aboriginal mothers: a retrospective cohort study. BMC Public Health. 2016;16:461.

35. Hanly M, Falster K, Chambers G, et al. Gestational age and child development at age five in a population-based cohort of Australian Aboriginal and non-aboriginal children. Paediatr Perinat Epidemiol. 2018;32(1):114-125.

36. Zubrick S, Silburn S, Lawrence D, et al. The Western Australian Aboriginal Child Health Survey: The Social and Emotional Wellbeing of Aboriginal Children and Young People. Perth Curtin University of Technology and Telethon Institute for Child Health Research, 2005.

37. Tran NK, Van Berkel SR, van IMH, . Alink LRA. The association between child maltreatment and emotional, cognitive, and physical health functioning in Vietnam. BMC Public Health. 2017;17(1):332.

38. Brinkman S, Gregory T, Harris J, Hart B, Blackmore S, Janus M. Associations between the early development instrument at age 5 , and reading and numeracy skills at ages 8,10 and 12: a prospective linked data study. Child Indic Res. 2013;6(4):695-708.

39. Waterston T, Alperstein G, Stewart BS. Social capital: a key factor in child health inequalities. Arch Dis Child. 2004;89(5):456-459.

\section{SUPPORTING INFORMATION}

Additional supporting information may be found online in the Supporting Information section.

How to cite this article: Strobel NA, Richardson A, Shepherd CCJ, et al. Modelling factors for Aboriginal and Torres Strait Islander child neurodevelopment outcomes: A latent class analysis. Paediatr. Perinat. Epidemiol.. 2020;34:50-61. https:// doi.org/10.1111/ppe.12616 